\title{
The impact of palliative care education and training program on the resident physicians
}

\author{
Jing Chang ${ }^{1 *}$, Zhuoran $\mathrm{Qi}^{1 *}$, Shan Jiang ${ }^{1}$, Lihong $\mathrm{Li}^{2}$, Qianmei Sun ${ }^{1 \wedge}$ \\ ${ }^{1}$ Department of Internal Medicine, Beijing Chao-yang Hospital, Capital Medical University, Beijing, China; ${ }^{2}$ Department of Medical Education, \\ Beijing Chao-yang Hospital, Capital Medical University, Beijing, China \\ Contributions: (I) Conception and design: J Chang, Z Qi, Q Sun; (II) Administrative support: Q Sun; (III) Provision of study materials or patients: L \\ Li; (IV) Collection and assembly of data: S Jiang; (V) Data analysis and interpretation: J Chang, Z Qi, Q Sun; (VI) Manuscript writing: All authors; (VII) \\ Final approval of manuscript: All authors. \\ "These authors contributed equally to this work. \\ Correspondence to: Qianmei Sun. Beijing Chao-yang Hospital, Capital Medical University, Gong-Ti South Road 8\#, Chao-Yang District, Beijing, \\ China. Email: sunqianmei5825@126.com.
}

Background Due to the advancements in medicine coupled with the aging population, palliative care has become widely needed. In many countries, medical students are trained in palliative care in their postgraduate courses. However, palliative care education is not available as an independent course or standardized training for residents in China.

Methods: This parallel randomized controlled trial was conducted in the Department of Internal Medicine, Beijing Chao-yang Hospital, Capital Medical University, between June 2016 and August 2017. The aim of the study was to explore the impact of the palliative care education and training program on 72 residents who were trained in standardization and were randomly divided into experimental and control groups at the ratio 1:1. The experimental group received resident physician standardized training and palliative care training program, while the control group received only standardized training. Standardized training included training in humanistic medical skills. The two groups were tested after training. A questionnaire survey was carried out to analyze the effect of palliative care education in humanistic medical skills.

Results: The total score of humanistic medical skills assessment of residents in the experimental group was higher compared to the control group $(82.92 \pm 8.39$ vs. $77.36 \pm 7.41, t=2.978, \mathrm{P}=0.004)$. The experimental group performed better in terms of medical skills and the ability to care for dying patients.

Conclusions: Palliative care education and training program should be required for residents as it is very useful. The purpose of palliative care education is to translate the knowledge in practice, truly implement the idea of palliative care, and relieve patients of terminal discomfort. The educational promotion of palliative care is of great value in China.

Keywords: Palliative care; education; resident physicians

Submitted Aug 18, 2020. Accepted for publication Dec 10, 2020.

doi: 10.21037/apm-20-1625

View this article at: http://dx.doi.org/10.21037/apm-20-1625

\footnotetext{
$\wedge$ ORCID: 0000-0002-1928-7772.
} 


\section{Introduction}

While the extension of life expectancy is generally positive and beneficial, it may pose certain challenges related to dying with dignity and peace. Due to the degeneration of various human functions, elderly people are prone to cardiopulmonary damage, kidney failure, tumors, and other chronic diseases. According to the International Agency for Research on Cancer, there were over 18 million newly diagnosed cancer cases worldwide and 9.6 million cancer death cases in 2018 (1). Palliative care, which is provided to a patient who suffers a life-threatening disease, implies doctors, nurses, and other professionals who as a team provide patients and their families with physical, psychological, and spiritual medical services. Palliative care emphasizes patients and their families' needs, rather than the treatment of the illness itself. It can help patients to maximize their quality of life and reduce illness burden in the last limited time (2-4).

Over recent years, some countries have included palliative care as a part of the medical curriculum, intending to help medical students gain an accurate perspective of life and death (5). Ireland, Germany, the United Kingdom, and other European countries have not only begun to train physicians in palliative care but already have specific professional assessment systems (6). By contrast, the development of palliative care is struggling in economically undeveloped areas, hampered by multiple challenges, such as insufficient knowledge and the public's weak consciousness (7). In China, the implementation of palliative care has basically been stagnated over the past 30 years. Many hospital leaders give high praise to palliative care education, but only a small proportion of medical schools set independent palliative care courses. The survey of palliative care education among 282 medical universities in mainland China showed that only 11 out of the 173 schools that participated in the survey offered specific palliative care education courses, of which 2 were compulsory, and 9 were elective, and 18 universities offered palliative care programs, combined with other courses. Some medical schools offer undergraduate doctor-patient communication courses, in which palliative medicine content occupies 2 class-hours. Also, palliative medicine education as an independent course among postgraduate courses is only set up for students majoring in geriatrics and relative specialties. In the postgraduate courses, the medical schools provide palliative care courses mainly through classroom lectures as these are not required by the medical curriculum dictated by the Ministry of Education (8). Due to insufficient curriculum, little clinical practice course, and low clinical skills, some students are only familiar with the term palliative care but do not understand the key points of palliative care and do not use palliative care skills in clinical treatment. Palliative medical education relatively lacks experiential teaching, and it focuses more attention on the cultivation of communication skills and the ability to diagnose and treat diseases (9).

Humanistic medicine is a human-centered medical model that emphasizes the interaction of biological, psychological, social, and environmental factors on the human body's health and disease. It incorporates professional medical technology and spiritual support services, which can be said to be all-round care for life. Previous reports have shown that medical students' patient-centered skills and critical thinking skills are indispensable for humanistic medicine education (10). Over recent years, the humanistic medical curriculum requires medical students to possess medical expertise, as well as humanities competencies such as communication skills, professional ethics, values, and empathy $(11,12)$. Humanistic medical skills are also closely related to medical security and the personal career development of physicians $(13,14)$, which requires physicians to adapt and learn in practice.

In this study, we explored whether the application of palliative care teaching in the training of residents' humanistic medical skills could extend the humanistic medical skills of residents and improve the teaching quality of standardized training for residents. We present the following article in accordance with the CONSORT reporting checklist (available at http://dx.doi.org/10.21037/ apm-20-1625).

\section{Methods}

\section{Subjects and study design}

The present study was conducted in the Department of Internal Medicine of Beijing Chaoyang Hospital, Capital Medical University, Beijing, China, between June 2016 and August 2017. All procedures performed in this study involving human participants were in accordance with the Declaration of Helsinki (as revised in 2013). The study was approved by the Medical Ethics Committee of the Beijing Chao-yang Hospital, Capital Medical University (No. 2013-science-139) and informed consent was taken from all the subjects. It was a research project on the teaching and 
implementation of palliative care, which was registered in the hospital teaching system.

The selected subjects were all rotating residents who were undergoing standardized training for residents in the Department of Internal Medicine of Beijing Chaoyang Hospital. Baseline data was recorded, including educational background, school, whether they underwent palliative medical training course. Residents who had previously participated in any form of palliative medical training courses or had relevant clinical work experience were excluded.

According to our previous survey of geriatric physicians' population, the average humanistic medical skills' scores of physicians with and without palliative medical education were $80.6 \pm 7.8$ and $75.2 \pm 7.1$, respectively. Since fewer reference data were found, we referred to the results of the previous survey for the estimation of the sample size. Using PASS software version 11, the number of persons required for each group was $30(\alpha=0.05 ; 1-\beta=0.8 ; 2$-sided contrast). Considering the loss to follow-up rate of about $20 \%$, we increased the sample size to 36 persons per group.

If the subject was absent from the planned intervention process for any reason, this person would no longer be considered as a qualified subject, and then later teaching evaluation (including examination and questionnaire) was terminated. Researchers were asked to timely record the information.

This was a parallel controlled trial with a balanced random allocation of 1:1. Through the random number table generated by the computer, participants were divided into the experimental group $(\mathrm{n}=36)$ and the control group $(n=36)$. The randomly assigned sequence information was sealed in an opaque envelope and finally opened by a project manager who was blinded to the intervention and outcome evaluation of the study. This trial was a singleblind randomized controlled trial, in which the teaching evaluators were not aware of the group allocation.

The experimental group participated in training that was held in accordance with the standardized training of residents and palliative medical training, while the control group participated in the standardized training. Medical humanities skills were included in standardized training content.

\section{Palliative care education and training}

Palliative medical training consisted of three parts: theoretical teaching, role-playing, and clinical practice. The teachers who instructed and evaluated the subjects were trained in specialized courses, namely at Peking Union Medical College Hospital (PUMCH)-Johns Hopkins Geriatrics conference and Doctor-Patient Communication Teachers' training Program from the Chinese Medical Doctor Association. All teachers were certified members of the Palliative Medicine Branch of the Chinese Association Geriatric Research and Geriatrics Professional Committee of the Beijing Medical Branch of the Chinese Medical Association. The teachers developed the content of palliative care lectures from the internationally and nationally available resources, Quality End of Life Care for All (QELCA) (15), Palliative Care Education and Practice (PCEP) (16), PUMCH-Johns Hopkins Geriatrics conference, and Doctor-Patient Communication Teachers' training Program from the Chinese Medical Doctor Association. First, the members of the experimental group concentrated on 2 class hours of lectures. Lectures on palliative care mainly focused on the concept and core principles of palliative care, i.e., how to assess the main symptoms and psychological state of end-stage patients; how to care for patients from the physical, psychological, and spiritual level; how to improve the patient's quality of life. Next, role-playing was conducted within two weeks after the lecture. The teacher analyzed and explained the selected typical hospitalized cases based on theoretical lectures and answered residents' questions. The time was set to 2 class hours. In the clinical practice part, residents were grouped and then practiced on each other. Each group was composed of 3 to 6 residents and 1 instructor, where 2 residents acted as patient and their families, and the other residents started the doctor-patient communication exercises to deeply comprehend and master caring for patients at a physical, psychological, and spiritual level. After the role-playing exercises, teachers commented on their performances and corrected behavior when necessary. Finally, the residents practiced on the clinical cases under the guidance of their instructors for two months.

\section{Standardized training}

Simultaneously with the experimental group, the standardized training for medical residents was implemented in the control group. According to the standardized training plan, there were 2 difficult cases to discuss ( 2 hours per case), 1 small lecture ( 2 hours in total), and 2 rounds of teaching ( 2 hours per time) every week. Resident physicians conducted routine skills training twice 
a month, which covered basic medical skills such as pleural puncture, abdominal puncture, and cardiopulmonary resuscitation. Each resident was asked to write 2 complete inpatient medical records every month, which were revised and archived by the instructor. Clinical internship of the control group also received and managed patients for 2 months.

\section{Evaluation of teaching effectiveness}

The teaching effect was investigated in the form of a humanistic medical skills examination and a customized questionnaire survey. The examination adopted the objective structured clinical examination (OSCE) of standardized residents training examination in China, taking the real case "Lung cancer with multiple metastases, discussing further treatment plans with patients and their families" as the test topic. The uniformly trained physicians who acted as examiners evaluated humanistic medical skills on residents one-to-one. Every candidate's time was set to $8-10 \mathrm{~min}$. The detailed examination process was divided into three parts: students first read the case report, after which they acted as competent physicians and communicated with patients or their families played by the examiners and established a good doctor-patient relationship. After that, doctors and patients negotiated further diagnosis and treatment plans and finally reached an agreement on treatment. Referring to the scores criteria of the doctor-patient communication skills for the OSCE of standardized residents training examination, we have adapted and developed the following five competencies as evaluation indicators to evaluate palliative care education and training. Building a good doctor-patient relationship implies listening patiently, respecting patients, and gaining their trust. Informing the patient about the purpose of the conversation and the detailed explanation is to genteelly communicate the bad news and help the patient and family gradually accept it. Expressing empathy means to show understanding and care for the patient and family members. Responding positively to patient feedback implies that when patients and their families have disease-related problems or psychological burdens, the resident can provide professional explanations and spiritual comfort. Reaching a satisfactory therapeutic consensus means that both doctors and patients jointly choose a treatment that improves the patient's quality of life under the existing medical conditions. Twenty points for each assessment indicator $(0=$ lowest score and $20=$ highest score). We designed a self-assessment questionnaire for residents to better understand the degree of their interest in humanistic medicine, the actual doctorpatient communication skills, the degree of improvement of humanistic medical skills, the ability to care for dying patients, and whether they were willing to accept palliative care training. On questions 1 to 4 , the most satisfactory scores were 20 points, and the most dissatisfactory score was 0 points. The answer to question 5 was "Yes" or "No". Our main outcome measures were standardized test scores and questionnaires.

\section{Statistical analysis}

Data entry and management were done through EpiData3.1 database software. Data entry adopted a double entry and double-check method. SPSS version 22.0 statistical software was used for analyzing data. Continuous data were presented by mean \pm standard deviation, and categorical data were presented by the number of cases and percentages. We compared continuous data and categorical data between two groups by the independent sample t-test and chi-square test, respectively. No interim analysis was produced either when designing the trial or during the trial. In the bilateral test, $\mathrm{P}$ value $<0.05$ was considered statistically significant.

\section{Results}

The 72 residents recruited for this study were randomly divided into two groups, and all completed the trial process well. The average age of residents in the experimental group was $24.9 \pm 1.1$, with 11 males $(30.56 \%)$ and the average age of $25.3 \pm 1.1$, including 8 males $(22.22 \%)$ in the control group. The number of residents with a master or doctoral degree in the experimental was 24 , compared to 26 in the control group. There were no statistically significant differences between the two groups of residents in terms of age, gender, and educational background (Table 1).

Table 2 shows the comparison of humanistic medical skills test scores in two groups. The total score of humanistic medical skills tests of residents who received palliative care training was higher than those who received only standardized training, and the difference was statistically significant. Furthermore, resident physicians without palliative care training scored lower in informing the patients of the purpose of the conversation and expressing empathy $(\mathrm{P}<0.05$, both $)$.

The questionnaire recovery rate was $100.0 \%(n=72)$. Unlike the experimental group, residents in the control 
Table 1 Baseline characteristics of the two groups

\begin{tabular}{|c|c|c|c|c|}
\hline Variable & The experimental group $(n=36)$ & The control group $(n=36)$ & $t / \chi^{2}$ & $\mathrm{P}$ \\
\hline \multicolumn{5}{|l|}{ Gender [n (\%)] } \\
\hline Male & $11(30.56 \%)$ & $8(22.22 \%)$ & 0.437 & 0.596 \\
\hline Education background & 12 & 10 & & \\
\hline Master degree & 21 & 22 & 0.058 & 0.810 \\
\hline Doctor degree & 3 & 4 & 0.158 & 0.691 \\
\hline
\end{tabular}

Table 2 Humanities and medical skills test scores

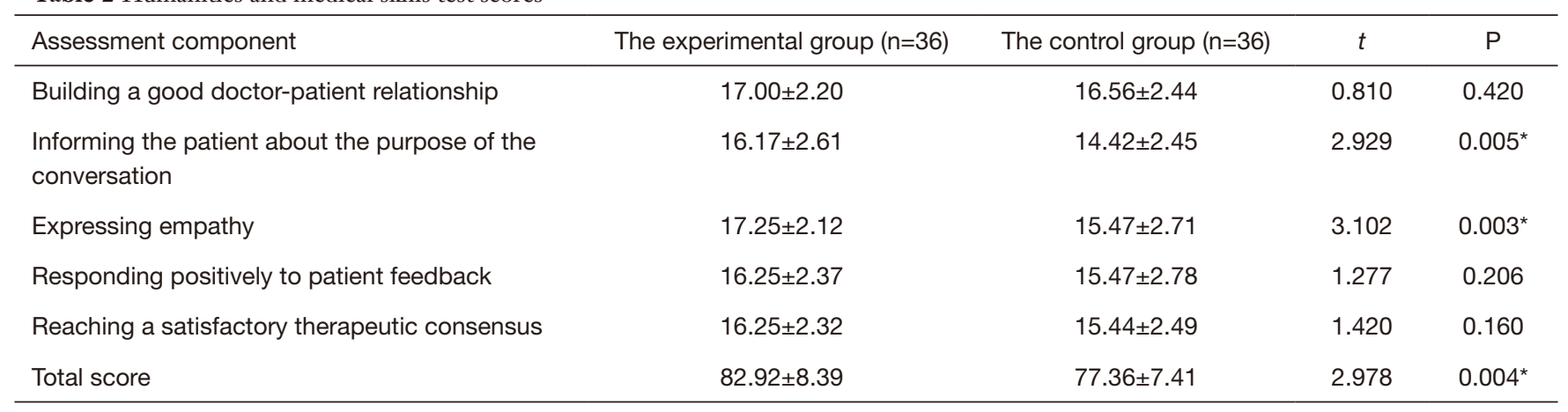

*, significant at $\mathrm{P}<0.05$.

Table 3 The results of questionnaire survey

\begin{tabular}{lccc}
\hline Question & The experimental group $(\mathrm{n}=36)$ & The control group $(\mathrm{n}=36)$ & $t / \chi^{2}$ \\
\hline $\begin{array}{l}\text { The degree of interest of residents in } \\
\text { humanistic medicine }\end{array}$ & $15.72 \pm 253$ & $14.64 \pm 3.31$ & 1.563 \\
$\begin{array}{l}\text { The actual doctor-patient } \\
\text { communication skills }\end{array}$ & $15.08 \pm 3.00$ & $14.33 \pm 2.26$ & 1.199 \\
$\begin{array}{l}\text { The degree of improvement of } \\
\text { humanistic medical skills }\end{array}$ & $16.78 \pm 1.99$ & $14.83 \pm 3.29$ & 3.035 \\
$\begin{array}{l}\text { The ability to care for dying patients } \\
\text { Willing to accept palliative care, } \mathrm{n}(\%)\end{array}$ & $16.44 \pm 2.25$ & $14.67 \pm 3.26$ & $0.003^{*}$ \\
\hline
\end{tabular}

*, significant at $\mathrm{P}<0.05$.

group performed relatively poorly in improving their humanistic skills and in caring for dying patients. The score of the degree of interest in humanistic medicine and the actual doctor-patient communication ability for the group trained in palliative care was slightly higher than that of the other group; however, there was no statistically significant difference. The detailed results are shown in Table 3.

\section{Discussion}

In this study, we found that residents receiving palliative care instruction performed better at humanistic medical skills, especially on informing patients about the purpose of the conversation and expressing empathy. Previous studies have shown that professional knowledge testing for 
the rotated residents improved by nearly $10 \%$ following online classes and clinical practice of palliative care (17). Palliative care advocates focusing on patients and their families and emphasize interdisciplinary team diagnosis and treatment so as to eventually ease complex disease symptoms and relieve psychosocial problems $(18,19)$. In the process of standardized training for resident physicians, systematic explanation of palliative care through lectures, and the continuous reinforcement of theoretical knowledge in teaching ward rounds and clinical practice, may make palliative care to become the basic skills of resident physicians, thus contributing to the cultivation of good doctor-patient relationship.

The higher score suggested that the residents in the experimental group were more efficient in taking care of dying patients compared to the control group $[(16.44 \pm 2.25)$ vs. (14.67 \pm 3.26$), \mathrm{P}=0.009]$. Under the influence of palliative medical education and practice, residents have made some improvements in alleviating the suffering of severe disease and actively interacting with patients (20). Residents who received education in palliative care may feel more confident and natural when providing professional medical assistance to patients (21). Apart from providing necessary medical services, which include the control of end-stage symptoms such as pain, palliative care also concerns psychological, spiritual, and social areas (22). Some Chinese oncologists believe that when terminal patients cannot be treated with traditional methods, palliative care may partially soothe their pain (23). Under the intervention of palliative care, the quality of life for patients with terminal cancer is significantly higher than that of patients with conventional treatment in the fourth month of follow-up (24). Emotional disorders, such as hopelessness, depression, and stress, occur when hospice workers provide bereavement care (25). Studies have shown that through spiritual care training, the mental health and spiritual nursing ability of nurses are enhanced (26). Resident physicians also face the diagnosis and treatment of advanced cancer patients in actual clinical work. Through the teaching of palliative care, the residents learn more about the physiological and psychological characteristics of dying patients so as to better face and manage dying patients.

The diagnosis and treatment of resident physicians is also an important part of providing palliative medical services for terminal cancer patients in actual clinical work. However, research on palliative medical education for residents and even undergraduate medical students is still very limited in China. The results showed that $72.2 \%$
$(26 / 36)$ and $44.4 \%(16 / 36)$ of residents in the experimental group and control group were willing to undergo palliative care training, which to some extent reflected the necessity of palliative care education. In American hospitals (over 300 beds), the need for palliative care is about $85 \%$ (27). Qualitative thematic analysis revealed that the elective courses in palliative care are very beneficial and stimulating for medical students (28). In China, few rotation bases set up palliative care training, and experts believe that palliative care is also an important part of the three-year resident physician training (29). Health and social care workers generally believe that palliative care should be an integral part of the undergraduate study of medical students (30). Influenced by traditional Chinese culture, many patients avoid talking about death with others and spend their last painful moments at home instead of being cared for by doctors in a hospital (31). Integrated knowledge training and practice, a short supply of participants, and the lack of policy support hinder the spread of palliative care education (32). The teaching and practice of palliative care are still in their immature stage in China. How to carry out palliative care teaching and how to establish a standard evaluation system determines the quality of life of patients.

The present study has some limitations. First, the data we collected on the standardized training of residents came from the same tertiary care hospital. Also, as this was a pilot study on palliative care education, there were some additional limitations related to the inherent bias of selfreporting results, variations in the clinically encountered cases that could impact education outcomes, and the lack of long-term outcomes that could help to understand the long-lasting impact of this intervention.

\section{Conclusions}

Palliative care training and practice programs are critical for the growth of resident physicians, where residents themselves have affirmed the usefulness and necessity of palliative care education. This article provided further support for palliative care that can provide comprehensive medical services for suffering patients. Our results revealed that residents could deepen the acquired theoretical knowledge in an interactive experience and clinical practice. The educational promotion of palliative care is of great value in China.

\section{Acknowledgments}

We wish to thank MedSci for editing the language of the 
manuscript.

Funding: This work was supported by the Beijing Municipal Science and Technology Commission [grant number Z171100000417055].

\section{Footnote}

Reporting Checklist: The authors have completed the CONSORT reporting checklist. Available at http://dx.doi. org/10.21037/apm-20-1625

Data Sharing Statement: Available at http://dx.doi. org/10.21037/apm-20-1625

Conflicts of Interest: All authors have completed the ICMJE uniform disclosure form (available at http://dx.doi. org/10.21037/apm-20-1625). The authors have no conflicts of interest to declare.

Ethical Statement: The authors are accountable for all aspects of the work in ensuring that questions related to the accuracy or integrity of any part of the work are appropriately investigated and resolved. All procedures performed in this study involving human participants were in accordance with the Declaration of Helsinki (as revised in 2013). The study was approved by the Medical Ethics Committee of the Beijing Chao-yang Hospital, Capital Medical University (No. 2013-science-139) and informed consent was taken from all the subjects. It was a research project on the teaching and implementation of palliative care, which was registered in the hospital teaching system.

Open Access Statement: This is an Open Access article distributed in accordance with the Creative Commons Attribution-NonCommercial-NoDerivs 4.0 International License (CC BY-NC-ND 4.0), which permits the noncommercial replication and distribution of the article with the strict proviso that no changes or edits are made and the original work is properly cited (including links to both the formal publication through the relevant DOI and the license). See: https://creativecommons.org/licenses/by-nc-nd/4.0/.

\section{References}

1. Bray F, Ferlay J, Soerjomataram I, et al. Global cancer statistics 2018: GLOBOCAN estimates of incidence and mortality worldwide for 36 cancers in 185 countries. CA Cancer J Clin 2018;68:394-424.
2. Lilley EJ, Cauley CE, Cooper Z. Using a Palliative Care Framework for Seriously Ill Surgical Patients: The Example of Malignant Bowel Obstruction. JAMA Surg 2016;151:695-6.

3. Center to Advance Palliative Care [Internet]. Virginia: The Association; c2002-2020 [cited 2020 Nov 6]. About Palliative Care 2017; [about 1 screens]. Available online: https://www.capc.org/about/palliative-care/

4. King's College London [Internet]. London: College; c2020 [cited 2020 Nov 6]. What is palliative care? 2016; [about 1 screens]. Available online: https://www.kcl.ac.uk/ cicelysaunders/about/what-is-palliativecare

5. Sweeney C, Lynch G, Khashan A, et al. The impact of a medical undergraduate student-selected module in palliative care. BMJ Support Palliat Care 2014;4:92-7.

6. Centeno C, Noguera A, Lynch T, et al. Official certification of doctors working in palliative medicine in Europe: data from an EAPC study in 52 European countries. Palliat Med 2007;21:683-7.

7. Abu-Odah H, Molassiotis A, Liu J. Challenges on the provision of palliative care for patients with cancer in low- and middle-income countries: a systematic review of reviews. BMC Palliat Care 2020;19:55.

8. Ye G, Mao J, Hu J, et al. Palliative care medical student education: a cross-sectional medical school survey in mainland China. BMJ Support Palliat Care 2019. [Epub ahead of print]. doi: 10.1136/bmjspcare-2019-002044.

9. Zhang J, Peng Y, Wang Z-R, et al. Comparison of hospice care education for the elderly in medical universities in China and Japan. Chin J Gerontol 2010;30:818-20.

10. Doukas DJ, McCullough LB, Wear S. Perspective: Medical education in medical ethics and humanities as the foundation for developing medical professionalism. Acad Med 2012;87:334-41.

11. Liu Y, Cheng X. An upcoming program for medical humanities education in Fudan University's School of Basic Medical Sciences. Biosci Trends 2017;11:152-3.

12. Jung H-Y, Kim J-W, Lee S, et al. A Study of Core Humanistic Competency for Developing Humanism Education for Medical Students. J Korean Med Sci 2016;31:829-35.

13. Tucker JD, Cheng Y, Wong B, et al. Patient-physician mistrust and violence against physicians in Guangdong Province, China: a qualitative study. BMJ Open 2015;5:e008221.

14. Piccinato CE, Rodrigues MLV, Rocha LA, et al. Characteristics of role models who influenced medical residents to choose surgery as a specialty: exploratory 
study. Sao Paulo Med J 2017;135:529-34.

15. St Christopher's Hospice [Internet]. London: Quality End of Life Care for All; c2000-2020 [cited 2013 May 16]. Available online: https://www.stchristophers.org.uk/

16. Harvard Medical School Center for Palliative Care [Internet]. Massachusetts: Palliative Care Education and Practice; c2013 [cited 2013 May 16]. Available online: https://pallcare.hms.harvard.edu

17. von Gunten CF, Twaddle M, Preodor M, et al. Evidence of improved knowledge and skills after an elective rotation in a hospice and palliative care program for internal medicine residents. Am J Hosp Palliat Care 2005;22:195-203.

18. Dans M, Smith T, Back A, et al. NCCN Guidelines Insights: Palliative Care, Version 2.2017. J Natl Compr Canc Netw 2017;15:989-97.

19. Ferris FD, Bruera E, Cherny N, et al. Palliative cancer care a decade later: accomplishments, the need, next steps -- from the American Society of Clinical Oncology. J Clin Oncol 2009;27:3052-8.

20. Peh TY, Yang GM, Krishna LKR, et al. Do Doctors Gain More Confidence from a Longer Palliative Medicine Posting? J Palliat Med 2017;20:141-6.

21. Karlen N, Cruz B, Leigh AE. Resident-Led Palliative Care Education Project. J Palliat Med 2016;19:428-36.

22. Ferrell BR, Twaddle ML, Melnick A, et al. National Consensus Project Clinical Practice Guidelines for Quality Palliative Care Guidelines, 4th Edition. J Palliat Med 2018;21:1684-9.

23. Gu X, Cheng W. Chinese oncologists' knowledge, attitudes and practice towards palliative care and end of

Cite this article as: Chang J, Qi Z, Jiang S, Li L, Sun Q. The impact of palliative care education and training program on the resident physicians. Ann Palliat Med 2021;10(3):2758-2765. doi: 10.21037/apm-20-1625 life issues. BMC Med Educ 2016;16:149.

24. Zimmermann C, Swami N, Krzyzanowska M, et al. Early palliative care for patients with advanced cancer: a clusterrandomised controlled trial. Lancet 2014;383:1721-30.

25. Lin WC, Fan SY. Emotional and cognitive barriers of bereavement care among clinical staff in hospice palliative care. Palliat Support Care 2020;18:676-82.

26. Hu Y, Jiao M, Li F. Effectiveness of spiritual care training to enhance spiritual health and spiritual care competency among oncology nurses. BMC Palliat Care 2019;18:104.

27. Morrison RS, Augustin R, Souvanna P, et al. America's care of serious illness: a state-by-state report card on access to palliative care in our nation's hospitals. J Palliat Med 2011;14:1094-6.

28. Centeno C, Ballesteros M, Carrasco JM, et al. Does palliative care education matter to medical students? The experience of attending an undergraduate course in palliative care. BMJ Support Palliat Care 2016;6:128-34.

29. Jiang S, Sun QM. Palliative care in medical teaching practice. Natl Med J China 2016;96:2212-3.

30. Preston N, Hasselaar J, Hughes S, et al. Disseminating research findings using a massive online open course for maximising impact and developing recommendations for practice. BMC Palliat Care 2020;19:54.

31. Li X, Xing YF, Chen ZH, et al. Palliative care in urban areas of China. Lancet Oncol 2013;14:e339.

32. Aldridge MD, Hasselaar J, Garralda E, et al. Education, implementation, and policy barriers to greater integration of palliative care: A literature review. Palliat Med 2016;30:224-39. 